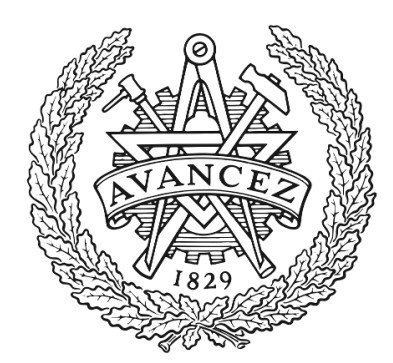

\title{
CHALMERS
}

UNIVERSITY OF TECHNOLOGY

\section{Measuring and Separating Conducted Three-Wire Emissions from a Fault-Tolerant, NPC Propulsion Inverter with a Split-Battery Using}

Downloaded from: https://research.chalmers.se, 2023-04-26 14:37 UTC

Citation for the original published paper (version of record):

Kersten, A., Oberdieck, K., Gossmann, J. et al (2021). Measuring and Separating Conducted Three-Wire Emissions from a Fault-Tolerant, NPC Propulsion Inverter with a Split-Battery Using Hardware Separators Based on HF Transformers. IEEE Transactions on Power Electronics, 36(1): 378-390. http://dx.doi.org/10.1109/TPEL.2020.3000586

N.B. When citing this work, cite the original published paper.

(O2021 IEEE. Personal use of this material is permitted.

However, permission to reprint/republish this material for advertising or promotional purposes 


\title{
Measuring and Separating Conducted Three-Wire Emissions from a Fault-Tolerant, NPC Propulsion Inverter with a Split-Battery using Hardware Separators based on HF Transformers
}

\author{
Anton Kersten, Student Member, IEEE, Karl Oberdieck, Jérôme Gossmann, Andreas Bubert, \\ Rolf Loewenherz, Markus Neubert, Torbjörn Thiringer, Senior Member, IEEE, and Rik W. De Doncker, Fellow, IEEE
}

\begin{abstract}
Conducted emissions on the traction battery's power cables in EVs must be limited to avoid unwanted EMI. When designing an EMI filter, it is advantageous to have information of the Common Mode (CM) and Differential Mode (DM) noise levels. This paper deals with the measurement and separation of the DC side's three-wire DM/CM noise of a fault-tolerant threelevel NPC inverter with a split-battery system. Two hardware separators, based on small circuit High Frequency transformers, were developed to identify the DC side's CM, line-DM and phase-DM noise levels. Their characterized $\mathrm{CM}$ and DM rejection ratios for the frequency range from $150 \mathrm{kHz}$ to $110 \mathrm{MHz}$ are at least $\mathbf{- 3 3} \mathrm{dB}$ and $\mathbf{- 2 1} \mathrm{dB}$, respectively. The separated noise of the NPC inverter was measured, using an inductive load, when operating the inverter with three-level and two-level modulation, resembling normal operation and a possible operation under fault, respectively. A simple three-wire CM model of the used testbed and the DM power module oscillation were derived to validate the separated noise's resonance peaks/valleys. It has been seen that the CM noise is dominant, especially below $10 \mathrm{MHz}$, except for the power module oscillations. Furthermore, when using the two-level modulation, in case of a clamping diode fault, the noise levels are increased by about $3 \mathrm{~dB}$.
\end{abstract}

Index Terms-Common mode (CM), Differential mode (DM), Electromagnetic compatibility, Electromagnetic emissions, Electromagnetic interference, Neutral point clamped inverter, Noise measurement.

\section{INTRODUCTION}

In modern electric vehicles, the proper functioning of all electronic devices must be ensured to guarantee an adequate and safe operation of the entire vehicle. The propulsion inverter, as the most powerful component, bears a high risk of Electromagnetic Interference (EMI) with other onboard or surrounding devices. Therefore, potential sources of Electromagnetic Emissions (EME) should be identified and mitigated during an early stage of the inverter's and the system's design process to reduce radiated and conducted emissions before applying shielding and filters. Standards, for example CISPR 25 [2], MIL-STD-461 [3] or SAE J1113/41 [4], classify

This article is an extension of the conference article "CM \& Line-Dm Noise Separation for Three-Level NPC Inverter with Connected Neutral Point for Vehicle Traction Applications" published at the ITEC 2019 [1].

A. Kersten and T. Thiringer are with the Division of Electric Power Engineering at Chalmers University of Technology, Gothenburg, Sweden (email: kersten@chalmers.se, torbjorn.thiringer@chalmers.se). K. Oberdieck A. Bubert, J. Gossmann, R. Loewenherz, M. Neubert and Rik W. De Doncker are with the Institute for Power Electronics and Electrical Drives, RWTH Aachen University, 52066 Aachen, Germany (e-mail: post@isea.rwthaachen.de). electric drivetrains by the noise levels on DC-power cables. However, the mentioned standards do not distinguish between Common Mode (CM) and Differential Mode (DM) quantities, whereas these are beneficial for the application of effective noise mitigation techniques, as for example EMI filters.

Due to increased voltage and current slew rates, widebandgap semiconductor converters can achieve high switching frequencies $\left(f_{\mathrm{sw}}>>20 \mathrm{kHz}\right)$ while maintaining a high propulsion inverter efficiency $(\eta>98 \%)$ [5]. The drawback is increased electromagnetic emissions [6]-[11]. This makes the design of EMI filters, particularly for high nominal DC-link voltages of $800 \mathrm{~V}$, for EVs very challenging [12]. In comparison to two-level inverters, multilevel inverters reduce conducted emissions due to a reduced output voltage swing [13][16], while maintaining a lower current THD [17]. Therefore, multilevel inverters are gaining in interest within the field of vehicle propulsion applications [18]-[20]. One of them is the three-level Neutral-Point-Clamped (NPC) inverter [21]. Its neutral point potential is usually formed by a capacitive voltage divider and an unbalance of the DC link voltages by the low-order harmonics, including the dominant third harmonic [22], should be mitigated [23], [24], especially at low speed. For example, a high torque demand at low speed operation (e.g. climbing a curb) can quickly drain one capacitor. The fault-tolerant, three-level NPC inverter, described in [25], utilizes a dual battery pack with two series connected battery modules. Through an additional connection of the capacitors' to the battery modules' midpoint, the capacitor voltages are not just tied to the battery modules' voltages, the topology also allows for a fault-tolerant operation of the power train in case of single semiconductor faults, referred to as "limp home" mode [25].

However, the additional neutral point connection forms a unique three-wire DC source, whereas the test procedures and limitations, stated in CISPR 25 [2], are usually applied to single DC sources (two-wire), requiring only two Line Impedance Stabilization Networks (LISNs) for the measurement of conducted emissions [26], [27]. Furthermore, the classical two-wire CM and DM consideration, as described in [9], cannot be applied to localize CM/DM resonances. Several solutions for hardware separators, utilizing passive or active circuitry like operational amplifiers, can be found in [9], [28]-[33]. Anyhow, these are either used for common two-level inverters [9], [28], [29] or for AC appliances (AC 


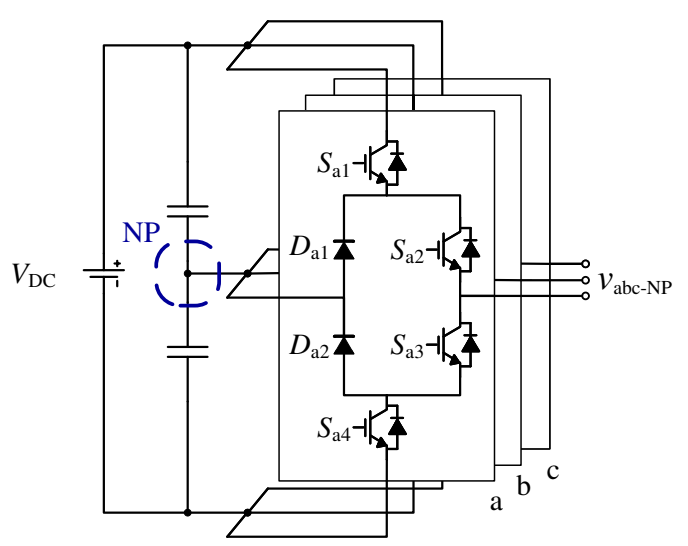

(a)

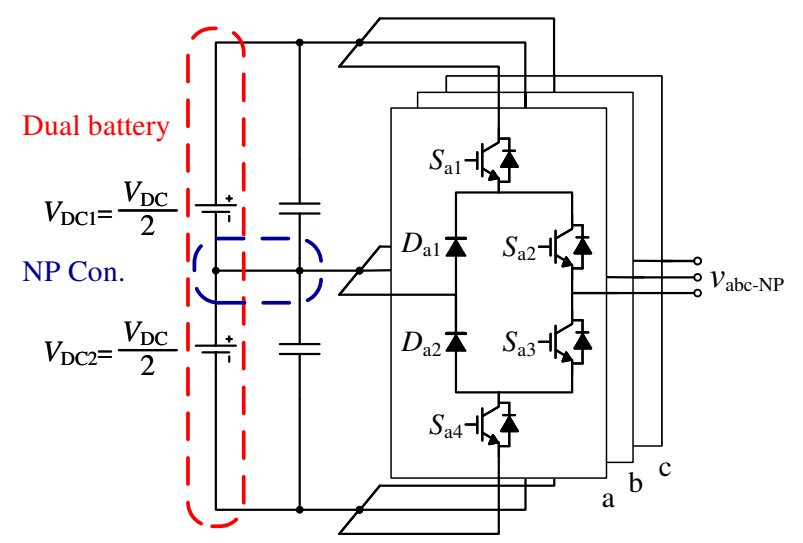

(b)

Fig. 1: Common three-level NPC inverter (a) without and (b) with additional NP connection including a split-battery [25].

side) [30]-[33], typically regulated by CISPR 14-1 [34]. Thus, the question arise: How to measure and separate the noise levels of the three-wire DC side of the fault-tolerant NPC inverter in accordance to CISPR 25?

Therefore, this paper shows how to measure the conducted emissions of the fault-tolerant NPC inverter according to CISPR 25 [2], using three LISNs, and the noise separation of the three-wire CM/DM is explained. Additionally, two compact hardware CM/DM separators, based on small circuit HF transformers, for the CM, line-DM and phase-DM noise levels were developed and are characterized. A test setup with an artificial machine load and an NPC prototype inverter are used for measurements. The characteristic resonances of the test setup are modeled and the inverter is operated with three-level and two-level modulation, resembling normal operation and operation under an open circuit fault of a clamping-diode, respectively.

\section{NPC InVERTER With Neutral Point Connection}

Commonly, the three-level NPC inverter is supplied by a single DC source, as can be seen in Fig. 1(a) [21]. Each capacitor has a nominal voltage rating equal to half of the full DC-link voltage. The switches are usually operated in pairs, so

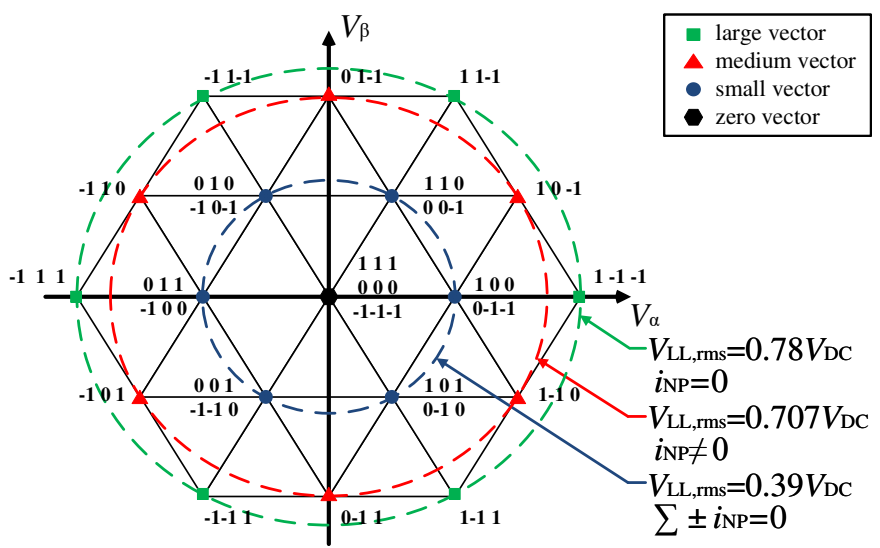

(a)

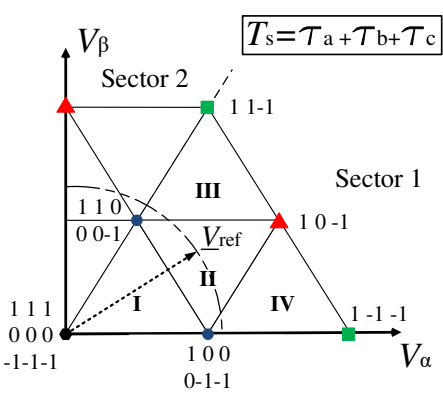

(b)

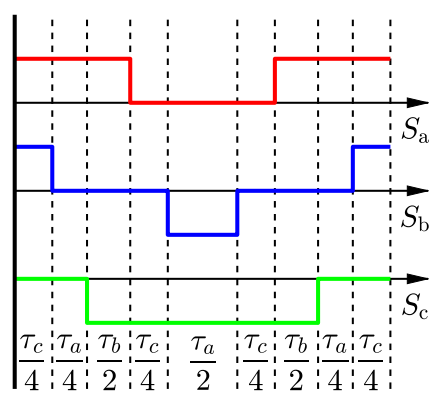

(c)
Fig. 2: (a) Three-level Space Vector Modulation (SVM) diagram in the $\alpha \beta$-plane and (b) voltage synthesis in Region II with (c) equal usage of redundant small vectors to reduce the neutral point current.

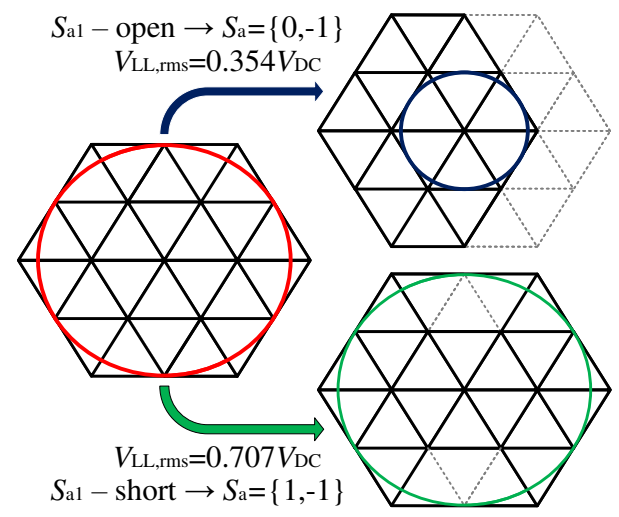

Fig. 3: Fault-tolerant operation of NPC inverter: adaption of valid space vectors in case of an open or short circuit fault of semiconductor switch $S_{\mathrm{a} 1}$.

that each phase has three valid switching states, which results in an instantaneous phase output voltage as

$$
v_{\mathrm{abc}-\mathrm{NP}}(S)=\frac{V_{\mathrm{DC}}}{2} S \text { with } \quad S=\{1,0,-1\} .
$$

Thus, transforming all valid 27 switching combinations into the $\alpha \beta$-plane, the space vector diagram as depicted in Fig. 2(a) is obtained. Space Vector Modulation (SVM) is a common approach to synthesize the reference output voltage by the time average of the three nearest vectors over one switching period [35]. As can be seen, the zero vector and each small vector have three or two valid switching states, respectively. Only the 
medium and large vectors do not have any redundancy. Using the zero switching state $S=0$ in any phase (small or medium vectors) leads to a current flowing into the neutral point of the DC-link capacitors that closes through the positive and the negative DC-link rail [22]. Thus, the neutral point current contains a substantial third-harmonic component, which can lead to an oscillation of the capacitor voltages, so that a switch can be exposed to a higher voltage than under nominal conditions. A proper selection of the small vectors must be ensured to keep the DC-link capacitors balanced. Several modulation techniques can be found in the literature [24], [35] and [23] to mitigate these oscillations. However, the adaption of the modulation technique typically comes with the cost of increased switching losses [23], [24], although it is also possible to balance the capacitor voltages over several switching cycles without adding additional switching events. Figures 2(b) and 2(c) depict, for instance, the voltage synthesis in Region II, equally sharing the medium vector time intervals, as implemented in Plexim's software tool PLECS [36]. Consequently, in case of an inverter fault, as an open or a short circuit switch fault, the valid space vectors would be compromised and the capacitor voltages would diverge without being balanced any longer. Thus, the neutral point would shift either to the positive or negative potential and the inverter's controllability would be lost [25].

A neutral point connection to a dual battery system, sometimes also referred to as split-battery system [37], as shown in Fig. 1(b), ties the capacitor voltages to the battery potentials. Thus, another low impedance path through the battery packs is provided for the third harmonic component. Thereby, the low-frequency voltage swing of the neutral point is eliminated and in case of a single inverter switch fault, as described in [25], the drive train can still be operated with limited power, referred to as limp home mode. For example, Fig. 3 depicts the remaining valid space vectors in case of an open or a short circuit fault of semiconductor valve $S_{\mathrm{a} 1}$. It can be seen that the maximum output voltage is not affected in case of a short circuit fault and only phase a must be operated in two-level modulation according to

$$
v_{\mathrm{a}-\mathrm{NP}}(S)=\frac{V_{\mathrm{DC}}}{2} S \quad \text { with } \quad S=\{1,-1\} .
$$

In case of an open circuit fault, the maxium output voltage is halved and all phases must be operated in single source operation according to

$$
v_{\mathrm{abc}-\mathrm{NP}}(S)=\frac{V_{\mathrm{DC}}}{2} S \quad \text { with } \quad S=\{0,-1\} .
$$

A detailed analysis about the fault tolerance of the NPC inverter with a neutral point connection can be found in [25]

\section{THREE-WIRE NOISE AND CM \& DM SEPARATORS}

Since the three-level NPC inverter, as shown in Fig. 1(b), is supplied by a dual battery with a connected neutral point, the DC side cannot be considered as a classical two-wire inverter system. Thus, it must be dealt with a three-wire or

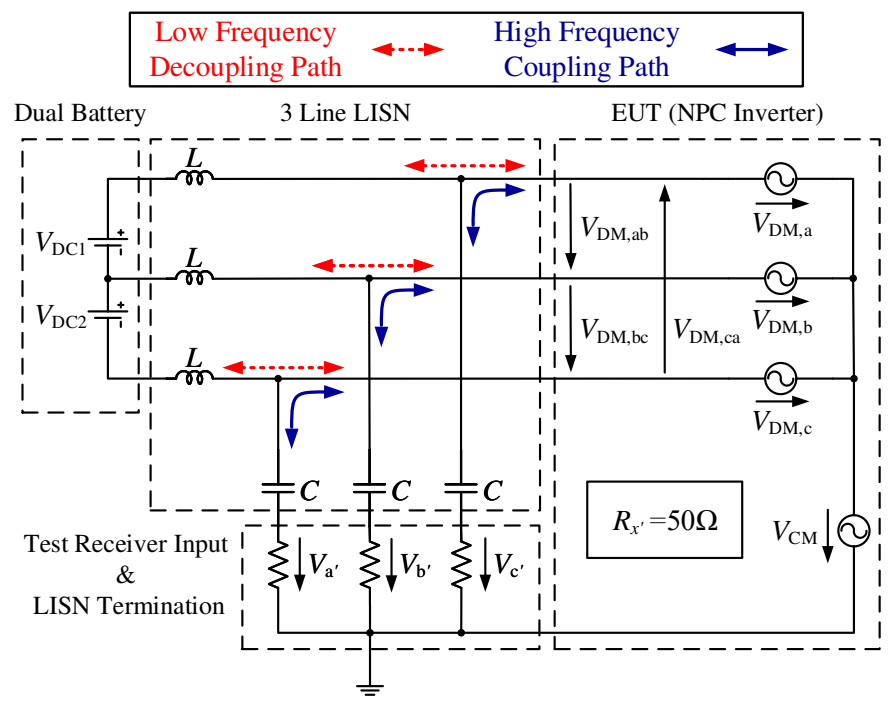

Fig. 4: Schematic of the noise measurement for the NPC inverter, including three LISNs. The LC-filter couples the high frequency noise of the EUT into the measurement receiver.

three-phase CM/DM system, depicted in Fig. 4 as the Equipment Under Test (EUT). The definition and separation of threephase DM/CM quantities are already known from classical three-phase AC systems, as for example described in [30][32] and [33]. The corresponding standard CISPR 14-1 [34] regulates the conducted EMI within the frequency range from $150 \mathrm{kHz}$ to $30 \mathrm{MHz}$. Hence, for the noise measurement according to CISPR 25 [2], three Line Impedance Stabilization Networks (LISN), often referred to as a special type of Artificial Mains Network (AMN), must be inserted between the split battery and the DC link capacitors' terminals of the NPC inverter to have a defined network impedance. These are required to couple the high frequency noise into the measurement equipment, whereas the low frequency components are still conducted via the DC-link rails. When measuring the noise levels, each output of the LISNs must be terminated by $50 \Omega$, either by the spectrum analyzer's input or by external terminations, to provide a symmetric measurement condition. As seen from the measurement scheme, shown in Fig. 4, the $\mathrm{CM}$ noise of the three-wire system is defined as the mean of the three LISN measurement outputs as

$$
V_{\mathrm{CM}}=\frac{V_{\mathrm{a}^{\prime}}+V_{\mathrm{b}^{\prime}}+V_{\mathrm{c}^{\prime}}}{3},
$$

whereas each of the three phase-DM noise spectra can be determined by the corresponding LISN measurement output and the CM noise as

$$
V_{\mathrm{DM}, x}=V_{x^{\prime}}-V_{\mathrm{CM}} \quad \text { with } \quad x=\{\mathrm{a}, \mathrm{b}, \mathrm{c}\} .
$$

Consequently, the line-DM noise spectra can be obtained by the subtraction of two phase-measurement outputs as

$$
V_{\mathrm{DM}, x y}=V_{x^{\prime}}-V_{y^{\prime}} \quad \text { with } \quad x y=\{\mathrm{ab}, \mathrm{bc}, \mathrm{ca}\} .
$$

Equations (4) to (6) are referred to as noise separation. Typically, swept-tuned spectrum analyzers acquire only the magnitude information over a broad frequency range, so that these cannot distinguish/separate between DM and CM 


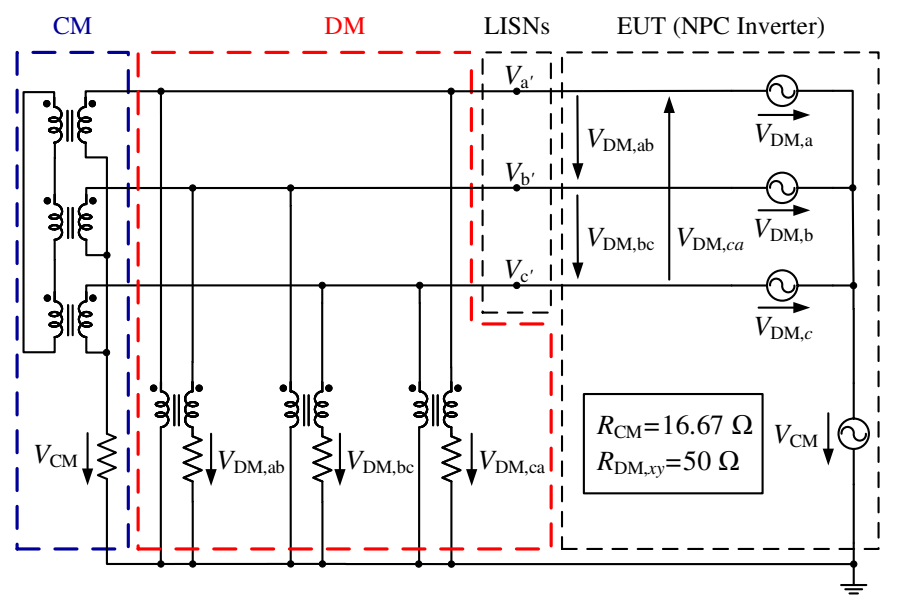

(a)

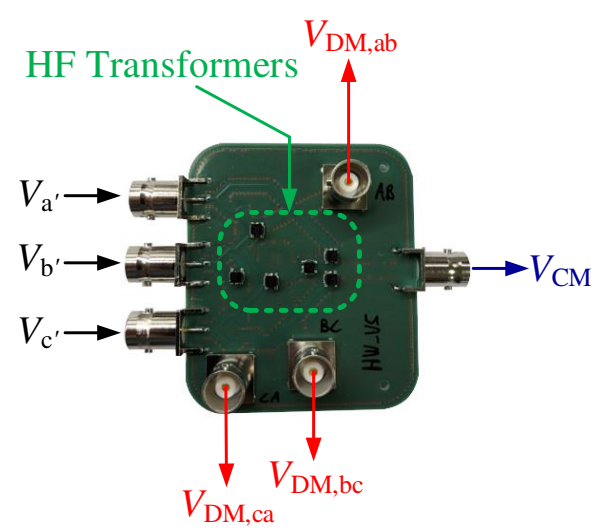

(b)

Fig. 5: CM and line-DM separation using HF transformers. (a) Schematic separation of the high frequency noise coupled into the LISN. (b) PCB of the corresponding separator.

quantities. On the other hand, real-time spectrum analyzers, such as a Fast Fourier Transform (FFT) analyzer, can acquire both magnitude and phase information, but the frequency range is limited to low frequency signals up to $150 \mathrm{kHz}$. Therefore, the noise separation is quite challenging, since the phase angle of the noise components must be taken into account over a broad frequency up to several $\mathrm{MHz}$ (CISPR 25: $150 \mathrm{kHz} \leq f \leq 108 \mathrm{MHz}$ ). In order to overcome the limited frequency range, an additional hardware separator, which is inserted between the three LISNs' outputs and the spectrum analyzer, could be used.

\section{A. Noise Separation Based on HF Transformers}

Within the scope of this article, two compact hardware separators based on small circuit HF transformers were developed for the DC side of the NPC inverter, including its additional neutral point connection. Both separator topologies are based on [30], [31], which were originally intended to be used for power electronic systems connected to the threephase mains (AC-side). Similar analyses regarding the design and characterization of hardware separators using small circuit transformers can be found in [32], [33]. Figures 5 and 6 show the equivalent circuit diagrams and the PCB designs of the

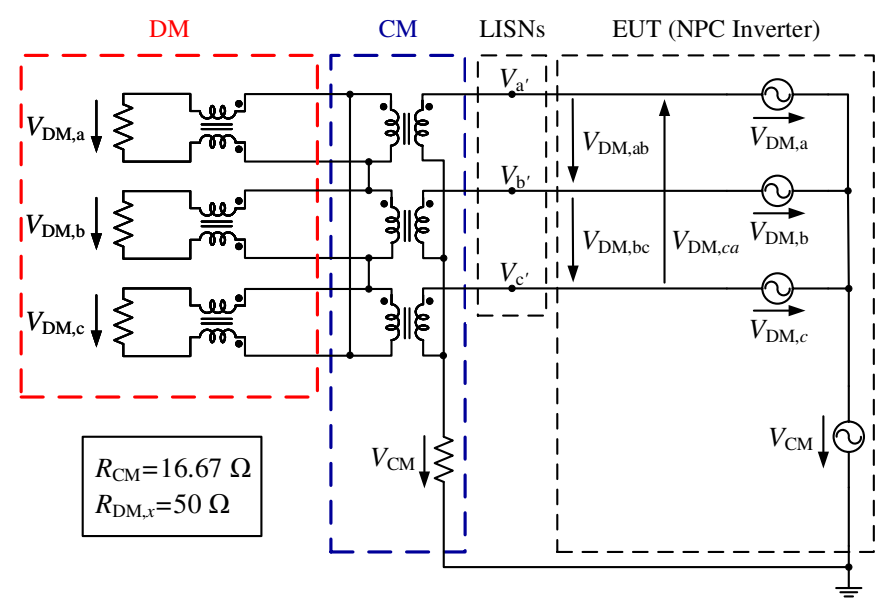

(a)

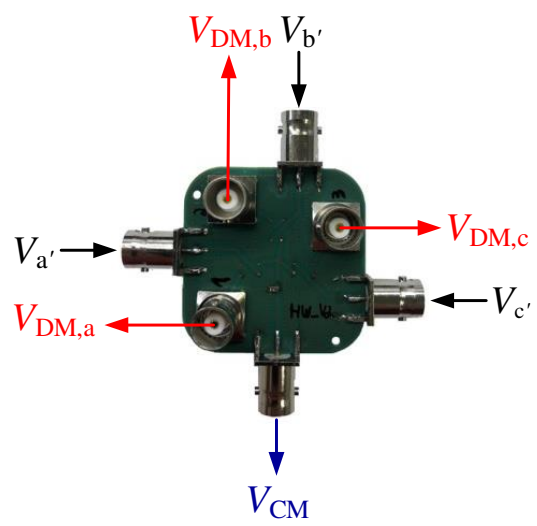

(b)

Fig. 6: CM and phase-DM separation using HF transformers. (a) Schematic separation of the high frequency noise coupled into the LISN. (b) PCB of the corresponding separator.

separators.

Both separators utilize the same CM separation technique, whereas the DM measurement differs. The first separator, shown in Fig. 5, measures the line-DM quantities. Here, the DM separation is placed directly at the terminals of the LISNs with an adjacent connection of the CM mode separation part. The second separator, shown in Fig. 6, measures the phase-DM quantities. Here, the CM separation is placed directly at the terminals of the LISNs with an adjacent connection of the CM mode separation part. It should be noted that, when using either of the separators, the output terminations $(50 \Omega)$ of the LISNs should not be affected. Thus, all DM outputs must be terminated by $50 \Omega$ and the $\mathrm{CM}$ output must be terminated by $50 / 3 \Omega$, as described in [30], [31]. Since the CM output of the separators has an internal $25 \Omega$ resistor mounted on the $\mathrm{PCB}$, the required termination resistances are achieved by using external $50 \Omega$ terminators or the input impedance of the spectrum analyzer. For the PCB realization, the TC1-42x+ [38] small circuit HF-transformers from Minicircuits were selected, achieving a very compact and cost effective separator design in comparison to [30]-[33]. The chosen HF transformers have an operational frequency range from $250 \mathrm{kHz}$ up to $400 \mathrm{MHz}$ with a typical insertion loss of 


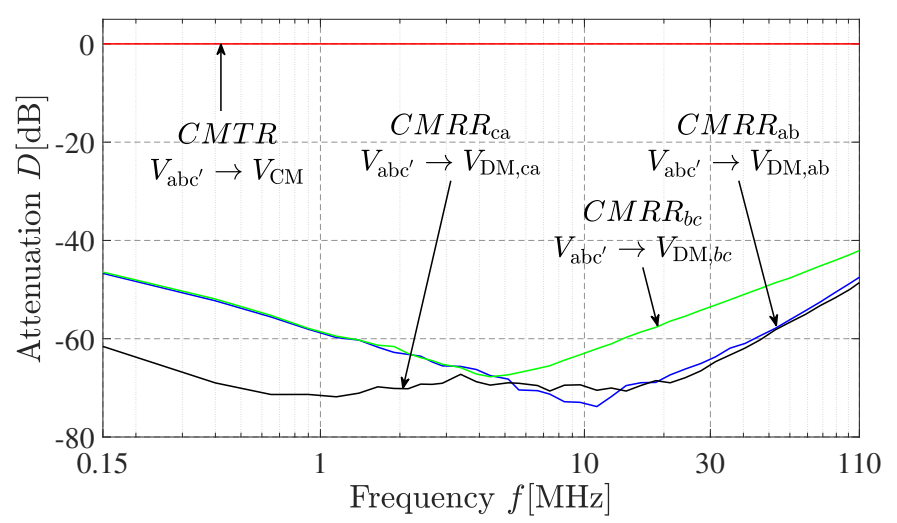

(a)

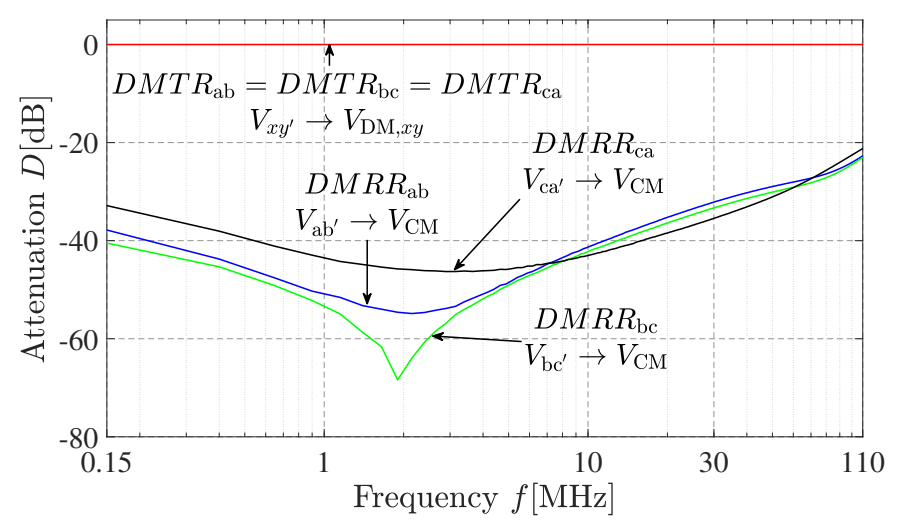

(b)

Fig. 7: (a) Common mode and (b) differential mode characteristic of the CM/line-DM separator.

$0.3 \mathrm{~dB}$. In Fig. 6 the HF transformers are not visible, since these are placed on the backside of the PCB. In the following pages, separator one and two are referred to as CM/line-DM and $\mathrm{CM}$ /phase-DM separator, respectively. The consideration of line or phase DM noise should be chosen in accordance with possible mitigation techniques. For example, if the traction system is on a floating potential, it might be more suitable to consider line-DM noise levels and, thus, to apply $\mathrm{X}$ instead of Y-capacitors [39].

\section{B. Characterization of the CM/line-DM Separator}

The performance of the three-phase CM/line-DM noise separator can be characterized by the following quantities:

1. CM Transmission Ratio $(C M T R)$ :

$$
\left.C M T R(f)=20 \mathrm{~dB} \cdot \log \left(\left|\frac{V_{\mathrm{CM}, \text { out }}}{V_{\mathrm{CM}, \mathrm{in}}}\right|\right)\right) \begin{aligned}
& V_{\mathrm{DM}, \mathrm{a}}=0 \\
& V_{\mathrm{DM}, \mathrm{b}}=0 \\
& V_{\mathrm{DM}, \mathrm{c}}=0
\end{aligned}
$$

2. Line-DM Transmission Ratios $\left(D M T R_{x y}\right)$ :

$\operatorname{DMTR}_{x y}(f)=20 \mathrm{~dB} \cdot \log \left(\left|\frac{V_{\mathrm{DM}, x y, \text { out }}}{V_{\mathrm{DM}, x y, \text { in }}}\right|\right) \mid \begin{aligned} & V_{\mathrm{DM}, y}=-V_{\mathrm{DM}, x} \\ & V_{\mathrm{DM}, z}=V_{\mathrm{CM}}=0\end{aligned}$

$$
\text { with } x y z=\{\text { abc, bca, cab }\}
$$

3. CM Rejection Ratios $\left(C M R R_{x y}\right)$ :

$$
\left.C M R R_{x y}(f)=20 \mathrm{~dB} \cdot \log \left(\left|\frac{V_{\mathrm{DM}, x y, \text { out }}}{V_{\mathrm{CM}, \text { in }}}\right|\right)\right) \begin{aligned}
& V_{\mathrm{DM}, \mathrm{a}}=0 \\
& V_{\mathrm{DM}, \mathrm{b}}=0 \\
& V_{\mathrm{DM}, \mathrm{c}}=0
\end{aligned}
$$

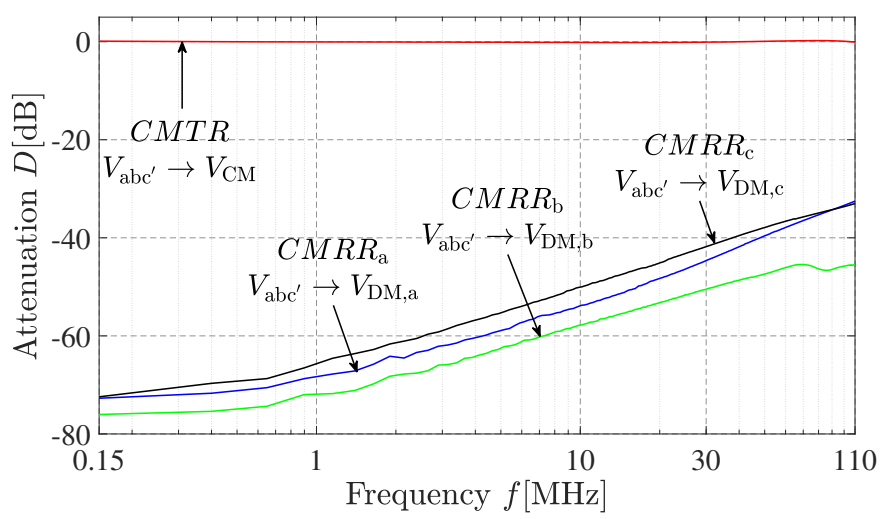

(a)

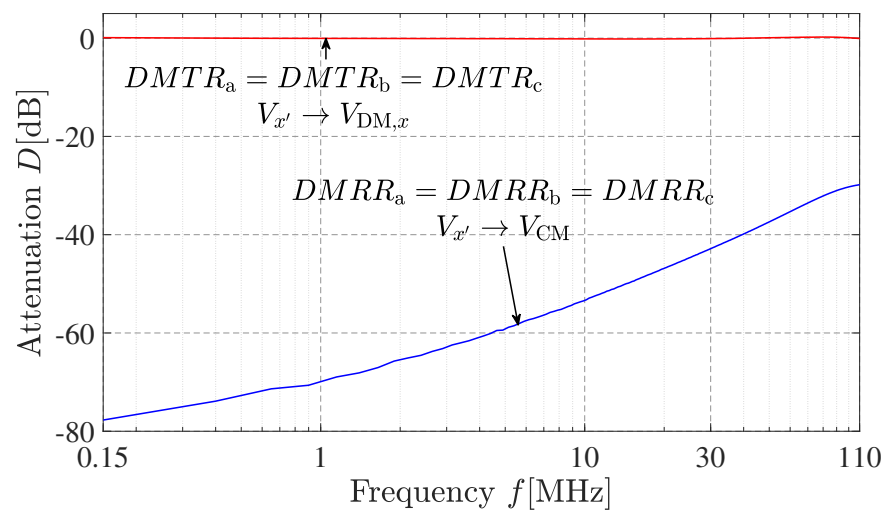

(b)

Fig. 8: (a) Common mode and (b) differential mode characteristic of the $\mathbf{C M}$ /phase-DM separator.

$$
\text { with } x y=\{\mathrm{ab}, \mathrm{bc}, \mathrm{ca}\}
$$

4. Line-DM Rejection Ratios $\left(D M R R_{x y}\right)$ :

$$
D M R R_{x y}(f)=20 \mathrm{~dB} \cdot \log \left(\left|\frac{V_{\mathrm{CM}, \text { out }}}{V_{\mathrm{DM}, x y, \text { in }}}\right|\right) \mid \begin{aligned}
& V_{\mathrm{DM}, y}=-V_{\mathrm{DM}, x} \\
& V_{\mathrm{DM}, z}=V_{\mathrm{CM}}=0
\end{aligned}
$$

$$
\text { with } x y z=\{\text { abc, bca, cab }\}
$$

The measured CM and line-DM characteristics of the separator are shown in Figs. 7(a) and 7(b), respectively. The Common Mode Transmission Ratio (CMTR) and the Differential Mode Transmission Ratios (DMRR) are about $0 \mathrm{~dB}$ for the considered frequency range, so that the $\mathrm{CM}$ and $\mathrm{DM}$ noises are transmitted undiminished to the corresponding outputs. The CMRRs of the three DM outputs are at least $-42 \mathrm{~dB}$, which corresponds to an attenuation of $0.79 \%$ relative to the input signal. The DMRR characteristics show an attenuation lower than $-32 \mathrm{~dB}$ for up to $30 \mathrm{MHz}$ and $-21 \mathrm{~dB}$ for up to $110 \mathrm{MHz}$, which corresponds to an attenuation relative to the input signal of $2.5 \%$ and $8.91 \%$, respectively. It can be seen that both CMRRs and DMRRs show a slight asymmetric behavior. This, however, is not crucial due to the high attenuation factors.

\section{Characterization of the CM/phase-DM Separator}

The performance of the three-phase CM/phase-DM noise separator can be characterized by the following quantities: 
1. CM Transmission Ratio $(C M T R)$ :

$$
C M T R(f)=20 \mathrm{~dB} \cdot \log \left(\left|\frac{V_{\mathrm{CM}, \text { out }}}{V_{\mathrm{CM}, \text { in }}}\right|\right) \begin{aligned}
& V_{\mathrm{DM}, \mathrm{a}}=0 \\
& V_{\mathrm{DM}, \mathrm{b}}=0 \\
& V_{\mathrm{DM}, \mathrm{c}}=0
\end{aligned}
$$

2. Phase-DM Transmission Ratios $\left(D M T R_{x}\right)$ :

$$
\begin{aligned}
& \left.\operatorname{DMTR}_{x}(f)=20 \mathrm{~dB} \cdot \log \left(\left|\frac{V_{\mathrm{DM}, x, \text { out }}}{V_{\mathrm{DM}, x, \text { in }}}\right|\right)\right) \begin{array}{l}
V_{\mathrm{DM}, y}=-V_{\mathrm{DM}, x} \\
V_{\mathrm{DM}, z}=-V_{\mathrm{DM}, x} \\
V_{\mathrm{CM}}=0
\end{array} \\
& \text { with } x y z=\{a b c, b c a, c a b\}
\end{aligned}
$$

3. CM Rejection Ratios $\left(C M R R_{x}\right)$ :

$$
\begin{gathered}
\left.C M R R_{x}(f)=20 \mathrm{~dB} \cdot \log \left(\left|\frac{V_{\mathrm{DM}, x, \text { out }}}{V_{\mathrm{CM}, \text { in }}}\right|\right)\right) \begin{array}{l}
V_{\mathrm{DM}, \mathrm{a}}=0 \\
V_{\mathrm{DM}, \mathrm{b}}=0 \\
V_{\mathrm{DM}, \mathrm{c}}=0
\end{array} \\
\text { with } x=\{\mathrm{a}, \mathrm{b}, \mathrm{c}\}
\end{gathered}
$$

4. Phase-DM Rejection Ratios $\left(D M R R_{x}\right)$ :

$$
\begin{aligned}
& D M R R_{x}(f)=20 \mathrm{~dB} \cdot \log \left(\left|\frac{V_{\mathrm{CM}, \text { out }}}{V_{\mathrm{DM}, x, \text { in }}}\right|\right) \begin{array}{l}
V_{\mathrm{DM}, y}=-V_{\mathrm{DM}, x} \\
V_{\mathrm{DM}, z=-V_{\mathrm{DM}, x}} \\
V_{\mathrm{CM}}=0
\end{array} \\
& \text { with } x y z=\{\mathrm{abc}, \mathrm{bca}, \mathrm{cab}\}
\end{aligned}
$$

The measured CM and phase-DM characteristics of the separator are shown in Figs. 8(a) and 8(b), respectively. Again, the Common Mode Transmission Ratio (CMTR) and the Differential Mode Transmission Ratios (DMRR) are about $0 \mathrm{~dB}$ for the considered frequency range, so that the $\mathrm{CM}$ and DM noises are transmitted undiminished to the corresponding outputs. The CMRRs of the three DM outputs are at least $-33 \mathrm{~dB}$, whereas the attenuation at low frequencies is up to about $-78 \mathrm{~dB}$. The DMRR characteristics show an attenuation of at least $-33 \mathrm{~dB}$, which corresponds to an attenuation of $1.6 \%$ relative to the input signal. It can be seen that the DMRRs are symmetrical, whereas the DMRRs show a slightly asymmetric behavior, however, less pronounced than for the CM/line-DM separator.

\section{Comparison with Available Hardware Separators}

In comparison to the available hardware separators in [30][33] the transformer size is significantly reduced. Due to the integrated small circuit design, the presented separators can be easily manufactured, achieving a compact design. In relation to [30]-[32] the transmission ratios are more constant along the whole frequency range and the rejection ratios for both $\mathrm{DM}$ and $\mathrm{CM}$ are improved by at least $10 \mathrm{~dB}$. Furthermore, the separator presented in [32] was only intended for frequencies up to $30 \mathrm{MHz}$.

\section{NPC INVERTER TESTBED FOR VALIDATION}

The previously described hardware separators were used to quantify the DM and CM noise levels of an NPC inverter with a connected neutral point, so that their performance could

\begin{tabular}{|c|c|c|}
\hline 1 DC Link Input & 3 DC Link Bus Bars & 5 Gate Drivers \\
\hline 2 Baseplate & 4 DC Link Capacitors & 6 Coolant Inlet/Outl \\
\hline
\end{tabular}
be validated. The prototype of the IGBT-based NPC inverter can be seen in Fig. 9. It utilizes the SKM300MLI066TAT three-level half-bridge modules from Semikron, with a nominal blocking capability of $600 \mathrm{~V}$ and a current rating of $300 \mathrm{~A}$ [40]. A nominal DC-link voltage of $V_{\mathrm{DC}}=400 \mathrm{~V}$ was chosen, so that each DC-link capacitor was supplied by about $200 \mathrm{~V}$.

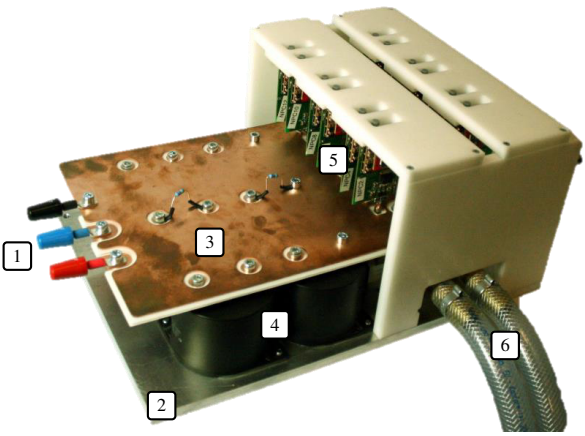

Fig. 9: Three-level NPC inverter prototype utilizing IGBT three-level half-bridge modules.

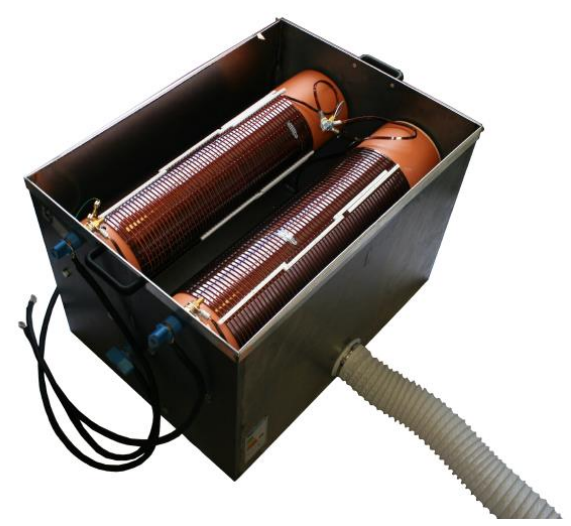

Fig. 10: Three-phase RL-load, air-core coil with forced air cooling.
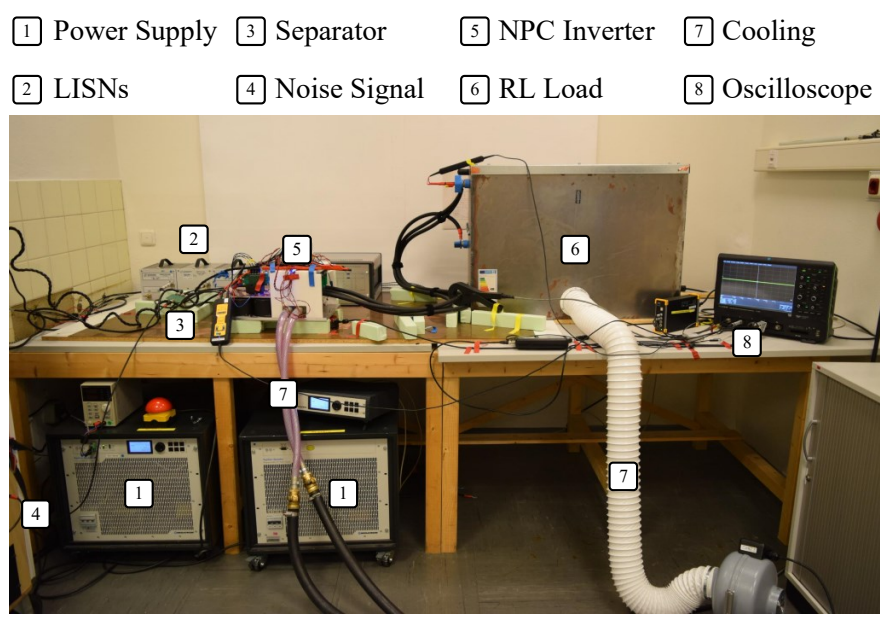

Fig. 11: EMI measurement testbench for three-level NPC inverter.

In a real application, a DC link voltage of $800 \mathrm{~V}$ would be an appropriate choice for the chosen IGBT blocking voltage capability. A custom-made three-phase RL-load, utilizing an air-core coil, was used as an Artificial Machine Load (AML), as shown in Fig. 10. The AML is suggested to mimic an induction machine at standstill. Due the absence of a back emf, the derivative of the current ripple $(\mathrm{di} / \mathrm{dt})$ is theoretically the highest [12], [41]. In an actual application, when using an 


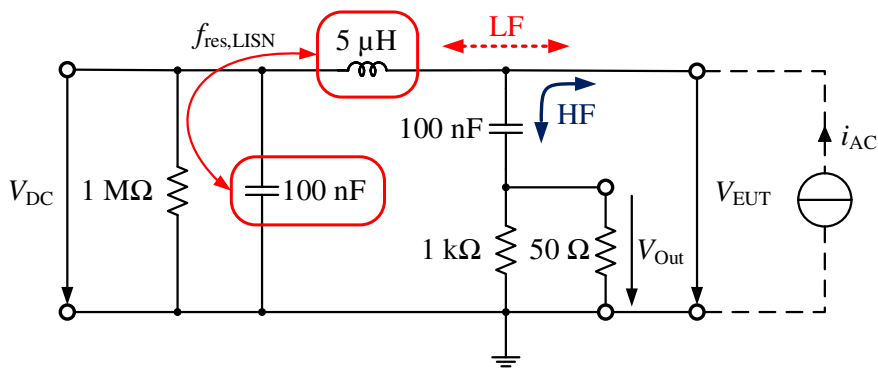

(a)

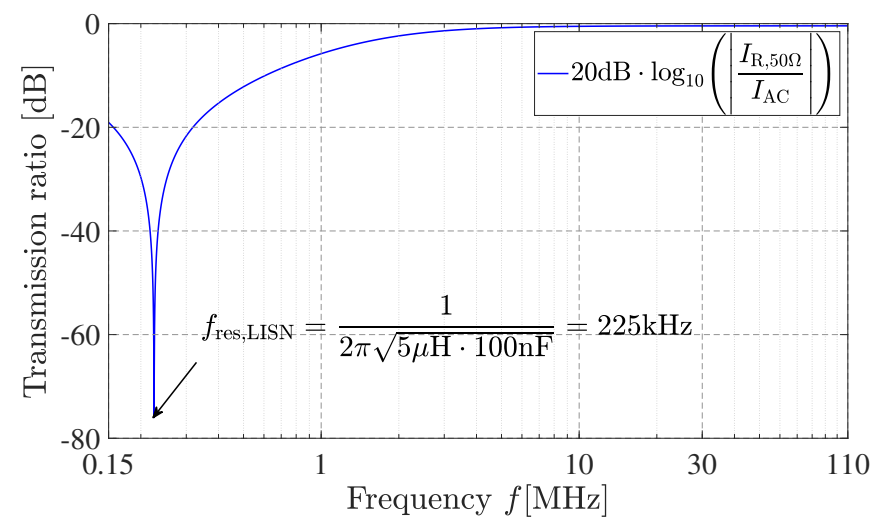

(b)

Fig. 12: (a) Equivalent circuit of an ideal LISN and (b) transmission ratio with high attenuation at a resonance frequency of $225 \mathrm{kHz}$.

electric machine, the measurement results could be different. Each phase of the AML had a nominal inductance of $220 \mu \mathrm{H}$ and a resistance of about $50 \mathrm{~m} \Omega$, resulting in a power factor $\cos \phi$ close to zero. The current rating was about $125 \mathrm{~A}_{\mathrm{RMS}}$ when using forced air cooling. The complete laboratory test bench can be seen in Fig. 11, built according to the standard CISPR series 16 [42]. The surface of the test bench was covered by a copper sheet (ground plate). Spacers were used to have a defined distance of $5 \mathrm{~cm}$ between the test equipment and the ground plate.

\section{A. Noise Characteristic of Test Setup}

To actually validate the performance of the separators, the dominant $\mathrm{CM}$ and $\mathrm{DM}$ resonance frequencies of the testbed should be known. Therefore, the CM characteristic of the LISN and the AML are modeled and the approximate resonance frequency of the DM power module oscillation is calculated in the following subsection. For a complete CM/DM model, the DC link capacitors, including the busbars and their parasitics, would need to be considered as well. However, these do not significantly affect the dominant noise levels [43] and, therefore, these are not part of the article's scope.

1) CM Modeling of AML: Figure 12(a) depicts an ideal LISN fed by an AC swept current $i_{\mathrm{AC}}$. Considering the transmission ratio of the input and the output current, as shown in Fig. 12(b), a high attenuation of almost $-80 \mathrm{~dB}$ at a frequency of about $225 \mathrm{kHz}$ is observed. As emphasized in Fig. 12(a), this characteristic attenuation is actually caused by the low frequency decoupling inductor and the $100 \mathrm{nF}$

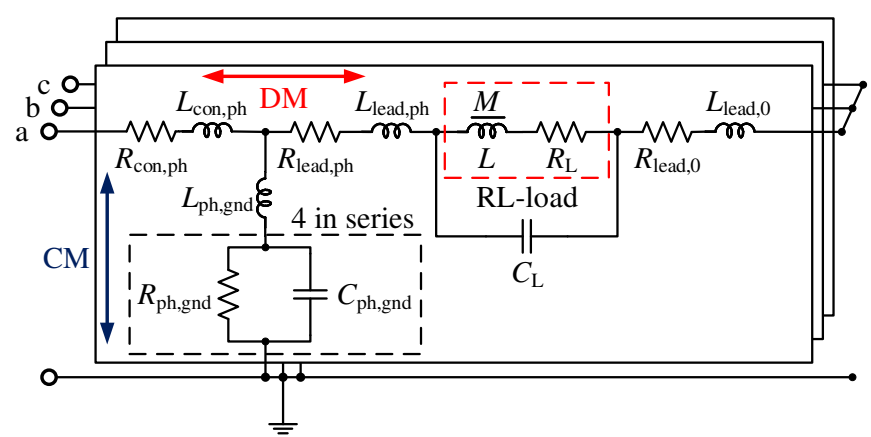

(a)

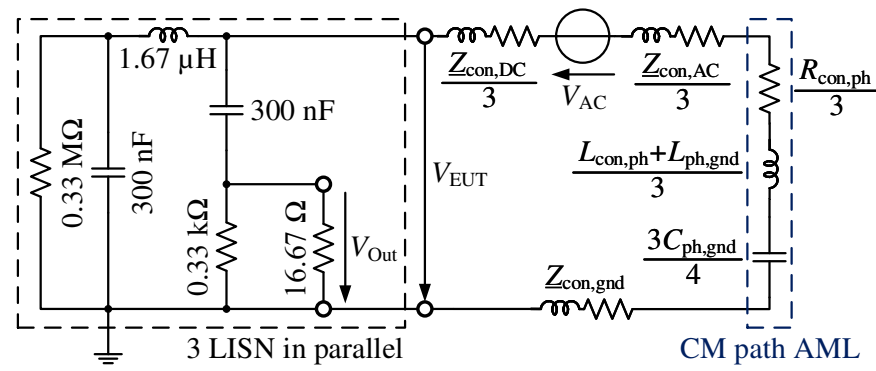

(b)

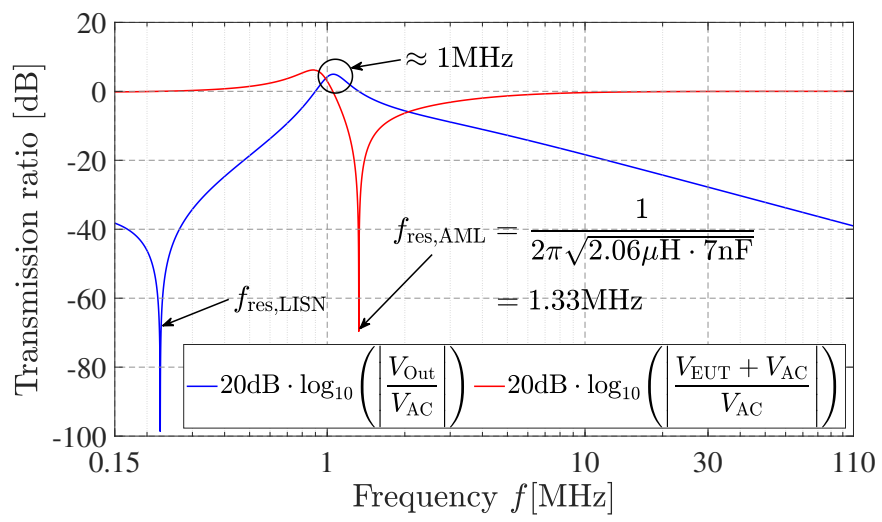

(c)

Fig. 13: (a) Equivalent circuit model of the AML, (b) CM model of the LISN and AML and (c) corresponding disturbance transmission ratio.

capacitor, forming a notch filter. The resonance frequency can be easily calculated as

$$
f_{\mathrm{res}, \mathrm{LISN}}=\frac{1}{2 \pi \sqrt{L C}}=225 \mathrm{kHz}
$$

The impedance of the AML has been previously modeled and parameterized in [12] and [44]. The modeled impedance network can be seen in Fig. 13(a). The DM path contains the impedance of the cable connections and the actual RL-load. The CM path resembles the parasitic current over the bearings of an electric motor to ground. For this purpose, 4 series-connected capacitors of $9.4 \mathrm{nF}$, giving a total capacitance of $2.35 \mathrm{nF}$, were implemented. Taking all three phases of the AML and the LISNs into account, a simple CM model [43], as depicted in Fig. 13(b), can be obtained. The disturbance source, the inverter, is now modeled as a simple voltage source $V_{\mathrm{AC}}$. The total CM impedance can be 


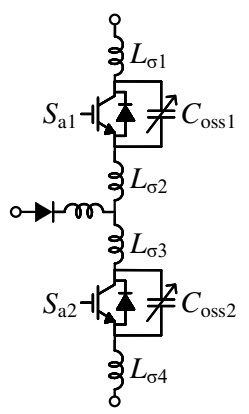

(a)

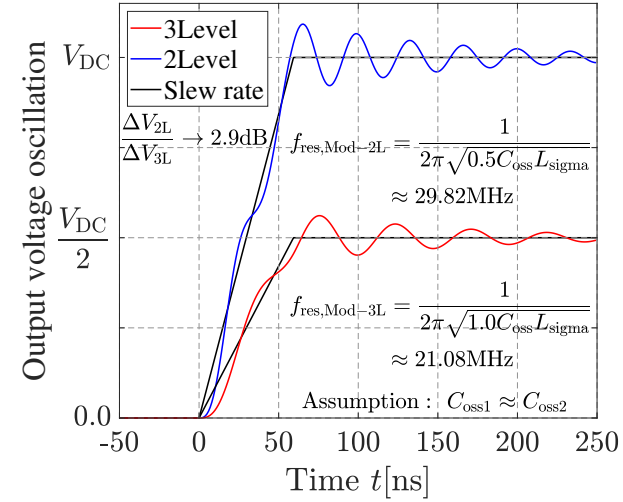

(b)
Fig. 14: (a) Modeled parasitics of an NPC inverter half-leg and (b) resulting power module oscillations using two-level and three-level output voltage modulation.

calculated as

$$
\begin{gathered}
\bar{Z}_{\mathrm{CM}, \mathrm{AML}+\mathrm{Con}}=\frac{\bar{Z}_{\mathrm{con}, \mathrm{DC}}}{3}+\frac{\bar{Z}_{\mathrm{con}, \mathrm{AC}}}{3}+\frac{R_{\mathrm{con}, \mathrm{ph}}}{3}+ \\
j \omega \frac{L_{\mathrm{con}, \mathrm{ph}}+L_{\mathrm{ph}, \mathrm{gnd}}}{3}+\frac{4}{j \omega 3 C_{\mathrm{ph}, \text { gnd }}}+\bar{Z}_{\mathrm{con}, \text { gnd }}
\end{gathered}
$$

which results in

$$
\bar{Z}_{\mathrm{CM}, \mathrm{AML}+\mathrm{Con}}=j \omega 2.06 \mu \mathrm{H}+2 \mathrm{~m} \Omega-j \frac{1}{\omega 7.05 \mathrm{nF}}
$$

A high attenuation at about $1.3 \mathrm{MHz}$ can be observed in the transmission ratio $\frac{V_{\mathrm{EUT}}+V_{\mathrm{AC}}}{V_{\mathrm{AC}}}$, as shown in red in Fig. 13(c). This resonance is caused by the $\mathrm{AML}$ and the resonance frequency can be accordingly calculated as

$$
f_{\mathrm{res}, \mathrm{AML}}=\frac{1}{2 \pi \sqrt{7.05 \mathrm{nF} \cdot 2.06 \mu \mathrm{H}}}=1.33 \mathrm{MHz} .
$$

The overall transmission ratio of the disturbance voltage $V_{\mathrm{AC}}$ and the output voltage of the LISNs $V_{\text {Out }}$ can be seen in Fig. 13(b), depicted in blue. On the one hand, the LISN causes an attenuation of the disturbance around the resonance frequency $f_{\text {res,LISN }}$. On the other hand, the AML forms a low impedance path at the resonance frequency $f_{\text {res, AML }}$, driving a disturbance into the LISN. Therefore, the combination of AML and LISN causes that the disturbance is actually worsened at about $1 \mathrm{MHz}$. The two mentioned CM resonances are mainly caused by the test setup. Therefore, these should be easily identified, using the separators, as CM noise. It should be noted that the shown CM model covers just the low frequency characteristics to explain the two mentioned resonance points.

2) Power Module Oscillations: A characteristic DM resonance of the inverter is typically caused by the semiconductor power modules. Figure 14(a) depicts the equivalent circuit of one NPC inverter half-leg, including its parasitics with $C_{\text {oss }}$ as the output capacitance of each IGBT and $L_{\sigma}$ as the stray inductance of the module packaging. The stray inductance of the used power modules was determined, using 3D FEM simulations, to be

$$
L_{\sigma, \text { half-leg }}=L_{\sigma 1}+L_{\sigma 2}+L_{\sigma 3}+L_{\sigma 4}=25 \mathrm{nH}
$$

and the IGBTs' output capacitance $C_{\mathrm{oss}}$ was estimated to be about $2.28 \mathrm{nF}$. Each time a switching action is performed, the resonance of the LC-circuit is triggered. However, it should be observed that the resonance frequency is different for two-level and three-level modulation. If two-level modulation is used, the output is switched between the positive and the negative DC link rail (full DC link voltage is switched), so that the combined capacitance corresponds to $0.5 \cdot C_{\mathrm{oss}}$. If three-level modulation is used, the output is either switched between the neutral and the positive or the neutral and the negative potential (half of the DC link voltage is switched), so that the resonance capacitance corresponds to $1 \cdot C_{\mathrm{oss}}$ (during the zero state, $S_{\mathrm{a} 2}$ is already switched and, thus, $C_{\mathrm{oss} 2}$ is shorted). Assuming that $C_{\text {oss } 1}=C_{\text {oss2 } 2}$, the module resonance frequency when using two-level and three-level modulation corresponds to

$$
f_{\mathrm{res}, \mathrm{Mod}-2 \mathrm{~L}}=\frac{1}{2 \pi \sqrt{0.5 \cdot C_{\mathrm{oss}} L_{\sigma}}}=29.81 \mathrm{MHz}
$$

and

$$
f_{\mathrm{res}, \mathrm{Mod}-3 \mathrm{~L}}=\frac{1}{2 \pi \sqrt{1 \cdot C_{\mathrm{oss}} L_{\sigma}}}=21.08 \mathrm{MHz} \quad,
$$

respectively. Figure 14(b) shows the modeled power module oscillations. Since the same inverter and gate driver circuitry are used, the voltage slew rate or the voltage swing of the two-level operation is twice of that of the three-level modulation. As can be seen in the graph, the voltage oscillation's magnitude of the three-level in comparison to the two-level modulation is reduced by about $2.9 \mathrm{~dB}$. However, it should be noted that the output capacitance has a nonlinear characteristic [45]. Therefore, the calculated resonance frequencies in (20) and (21) can slightly differ in reality. Nevertheless, the provided equations and illustrations provide a reasonable characterization of the power module oscillation when using two and three-level output voltage modulation.

\section{B. Inverter Output Voltage Modulation}

During the investigation, the inverter was operated either with three-level space vector modulation, as described in [36] and Section II, or with classical two-level space vector modulation (avoidance of small and medium vectors shown in Fig. 2 [25]), changing the instantaneous output voltage in (1) to

$$
v_{\mathrm{abc}-\mathrm{NP}}(S)=\frac{V_{\mathrm{DC}}}{2} S \quad \text { with } \quad S=\{1,-1\} .
$$

The two-level modulation should resemble an operation under an inverter fault condition, as for example an open circuit fault of a diode in the clamping path [25]. A switching frequency of $10 \mathrm{kHz}$ was chosen. An open-loop control approach, using a fixed modulation index, was selected. The blanking time and the voltage drop across the semiconductor switches were not taken into account. It should be noted that the switching frequency of a multilevel inverter is referred to as the average frequency at which a phase leg is operated and should not be misinterpreted as the average switching frequency of individual semiconductor switches [46]. The fundamental frequency $f_{1}$ was set to $500 \mathrm{~Hz}$ and the modulation indices were chosen to be $3.75 \%$ and $7.5 \%$ for the two-level and the three-level 


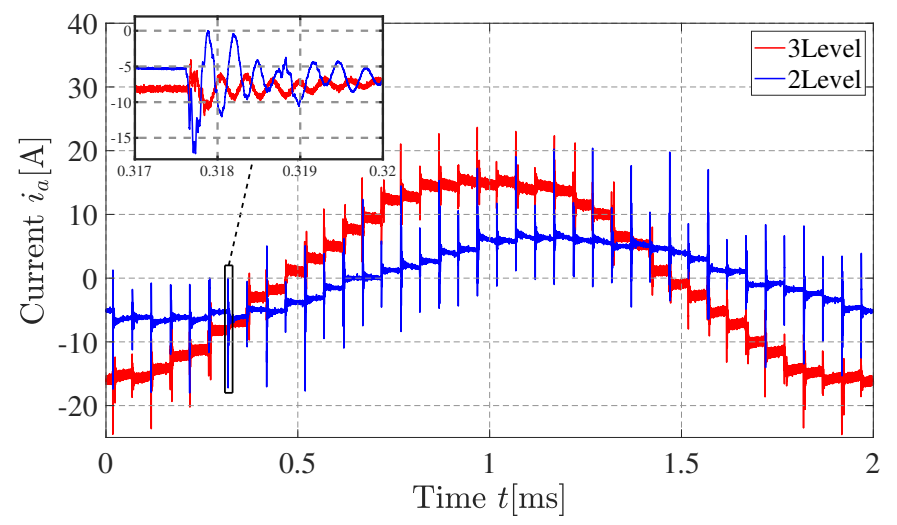

Fig. 15: Single-phase load currents for three-level and two-level operation.

modulation, respectively. It should be noted, the maximum possible modulation index was about $23 \%$ due to absence of a back-emf. Furthermore, due to the absence of the backemf, the derivative of the current ripple is unaffected by the modulation index. Thus, the noise levels are unaffected as well by the modulation index. Fig. 15 shows the load current in phase a when using two-level and three-level operation. It can be observed that a displacement current is triggered at each switching event. As shown in Fig. 15, the three-level modulation reduces the peak of the displacement current by about $50 \%$. It should be noted that no EMI filter is applied.

\section{QuANTIFICATION AND SEPARATION OF CONDUCTED ELECTROMAGNETIC EMISSIONS}

When operating the inverter, the outputs of the three LISNs were connected to the noise-separator and the measured noise signal was fed from the testbed to the spectrum analyzer. Figure 16 shows the spectra obtained at the outputs of the three LISNs measured with a peak detector. A Gaussian filter was selected. The spectrum analyzer's Resolution Bandwidth (RBW) was set to $3 \mathrm{kHz}$. Since the CISPR 25 recommends a Video Bandwidth (VBW) of at least three times the RBW [2], the spectrum analyzer automatically adjusted the VBW to $30 \mathrm{kHz}$, which resulted in a sweep time of about $16.5 \mathrm{~s}$. As described in Section III, three typical resonances were observed. One resonance valley occurs around $225 \mathrm{kHz}$, while a second dominant resonance peak is present at about $1 \mathrm{MHz}$. A smaller resonance peak is also located around $25 \mathrm{MHz}$. These three resonance points can be associated with the previously described LISN, AML and power module oscillations, respectively. As can be seen from the three LISNs' outputs, the module resonance is not symmetrical. The highest noise level is observed at the negative DC-link rail $\left(V_{\mathrm{c}^{\prime}}\right)$. Furthermore, it can be seen that the three-level in comparison to the two-level modulation does not only reduce the noise level by 3 to $6 \mathrm{~dB}$, it affects also the module resonance frequency as similarly described in (20) and (21).

\section{A. Separated Noise}

To validate the performance of the separators, the measured noise was separated into CM, line-DM and phase-DM quantities.

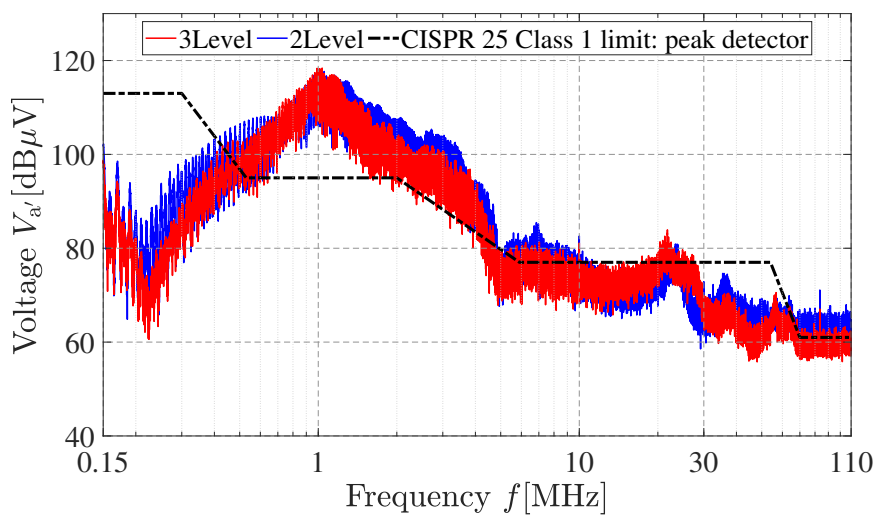

(a)

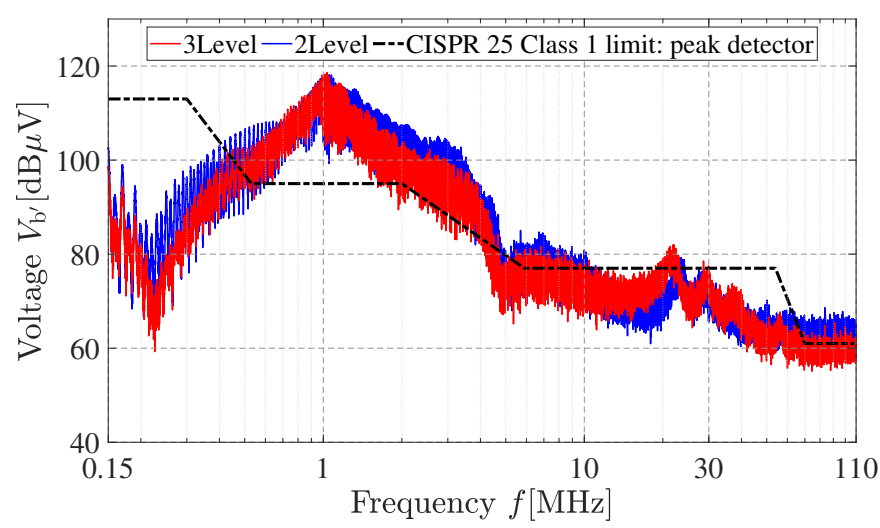

(b)

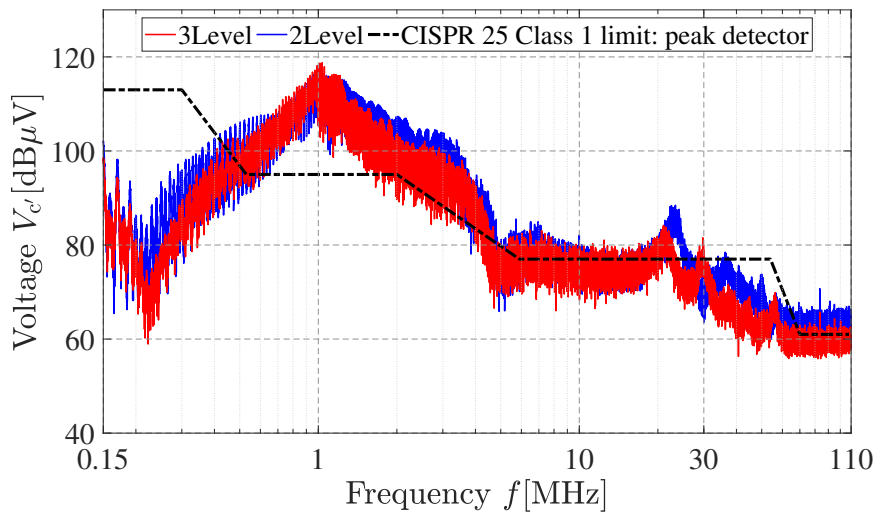

(c)

Fig. 16: Three and two-level noise spectra at (a) positive, (b) neutral and (c) negative DC link rail.

1) $C M \&$ Line-DM Noise: Figures 17 (a) and 17(b) show the separated $\mathrm{CM}$ and one line-DM $\left(V_{\mathrm{DM}, \mathrm{ab}}\right)$ spectrum, respectively, measured with the CM/line-DM separator. Since the three line-DM spectra show similar noise levels, just $V_{\mathrm{DM}}$,ab is shown here. Similar to the two-level inverter investigation in [9], the CM is also predominant for the three-level NPC inverter with connected neutral point. It can be seen that the noise levels using two-level operation are slightly increased by 3 up to $6 \mathrm{~dB}$ for both CM and DM. Furthermore, as modeled in Section III, it is observed that the LISN and AML resonances are driven by the $\mathrm{CM}$, whereas the module resonance is driven by the DM. Regarding the power module resonance, 


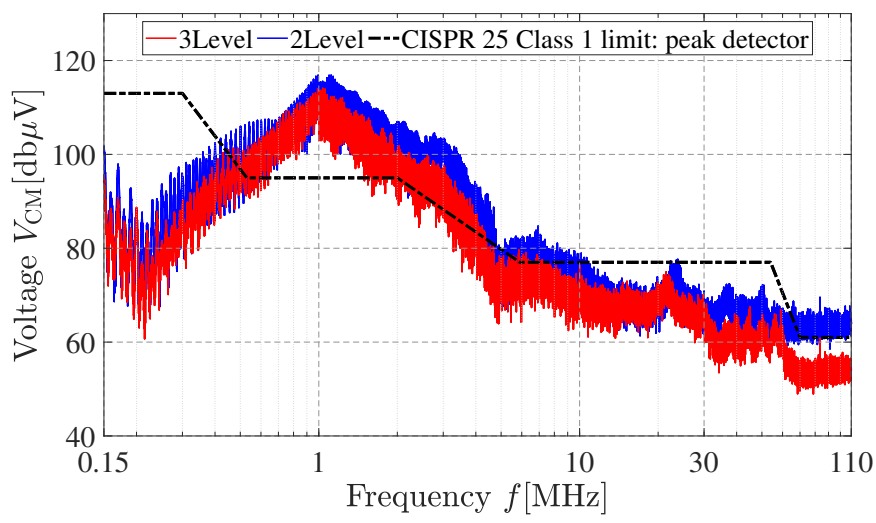

(a)

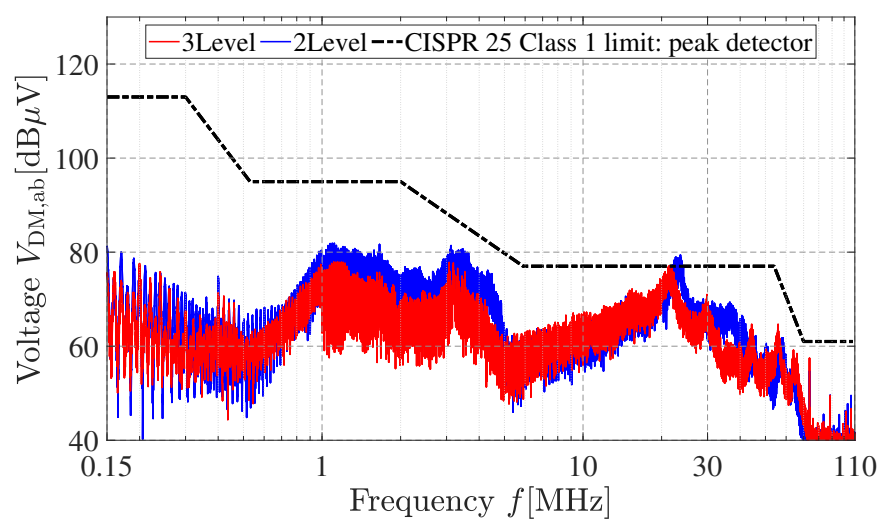

(b)

Fig. 17: Measured (a) CM and (b) line-DM ( $\left.V_{\mathrm{DM}, \mathrm{ab}}\right)$ noise, when operating with two-level and three-level modulation.

the two-level in comparison to the three-level modulation shifts the resonance frequency from about $25 \mathrm{MHz}$ to $21 \mathrm{MHz}$ and the noise level is reduced by about $3 \mathrm{~dB}$.

2) $C M$ \& Phase-DM Noise: The obtained results of the $\mathrm{CM} /$ phase-DM separator can be seen in Fig. 18. Regarding the CM, a similar noise spectrum as for the CM/line-DM separator was obtained, as can be seen in Fig. 18(a). Figures 18(b) and 18(c) show the phase-DM spectra $V_{\mathrm{DM}}$,a and $V_{\mathrm{DM}, \mathrm{b}}$, respectively. The third phase-DM spectrum $V_{\mathrm{DM}, \mathrm{c}}$ is not displayed, since it does not qualitatively differ from $V_{\mathrm{DM}, \mathrm{a}} \cdot V_{\mathrm{DM}, \mathrm{a}}$ shows a similar spectrum as $V_{\mathrm{DM}, \mathrm{ab}}$, while the phase quantities seem slightly increased compared to the line quantities. When in two-level operation, $V_{\mathrm{DM}, \mathrm{b}}$ shows a significant noise reduction in the range above $4 \mathrm{MHz}$, since the zero switching state of each phase leg is not used and the power module oscillation is not triggered. The spectrum at lower frequencies is not effected.

\section{B. Parasitic CM Current over Ground Plate}

Typically, the high voltage traction system in a car is isolated. Though, the unwanted parasitic currents, capacitively or inductively coupled, in the motor bearings [47] or the vehicle's chassis are other criteria to assess the EME of the traction inverter and, thus, can be used to verify the measured $\mathrm{CM}$ noise reduction. For this purpose, a current sensor was mounted on a flat copper bar between the inverter's

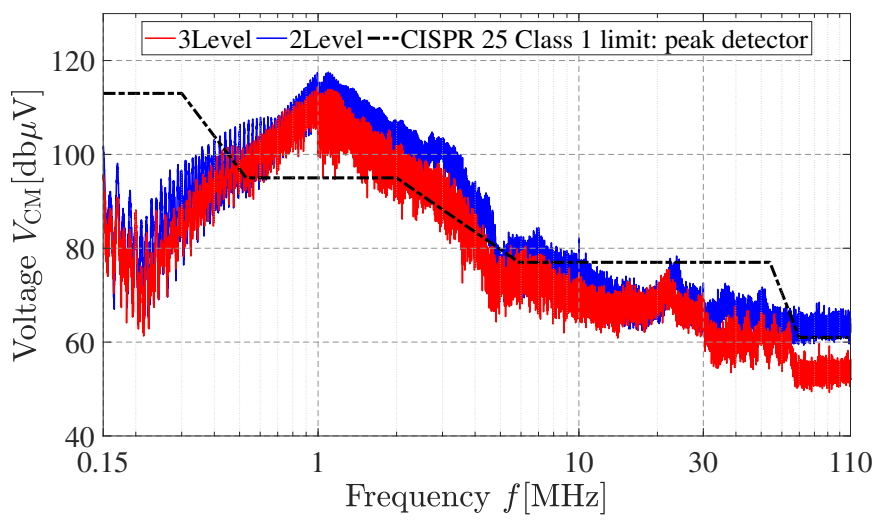

(a)

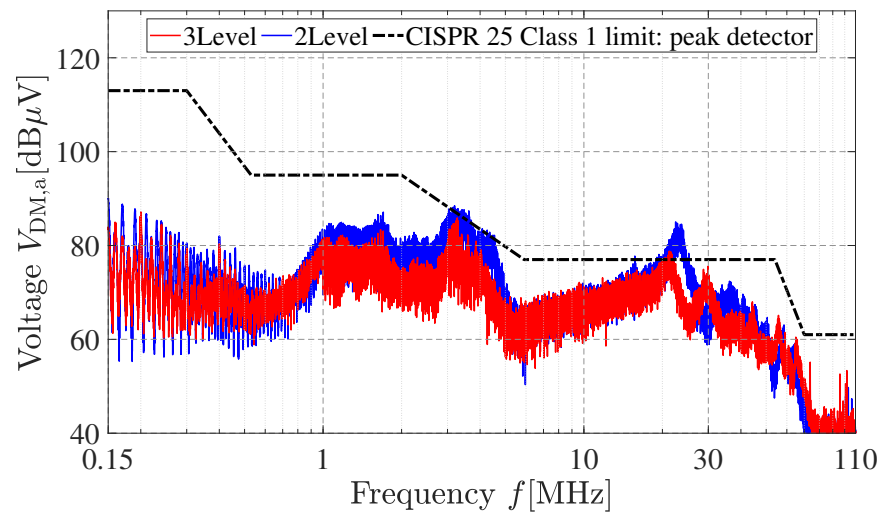

(b)

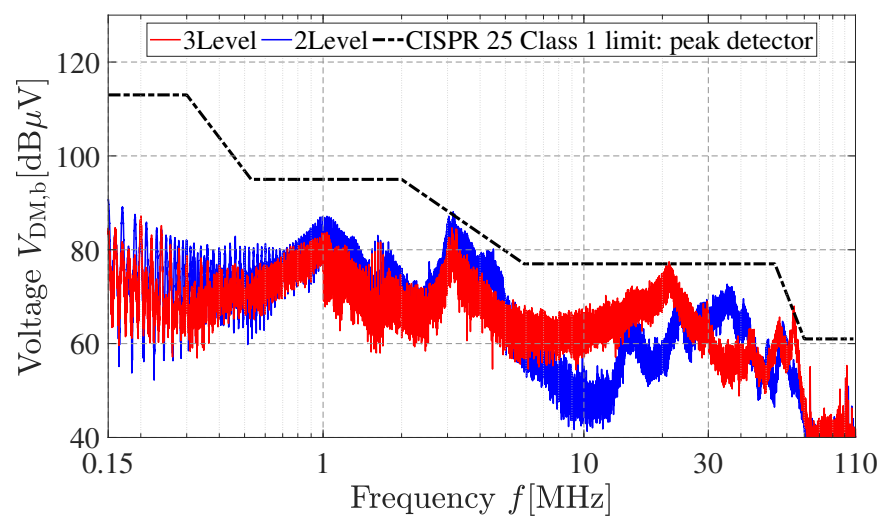

(c)

Fig. 18: Measured (a) CM and (b) phase-DM at positive $\left(V_{\mathrm{DM}, \mathrm{a}}\right)$ and $(\mathrm{c})$ neutral DC-link rail $\left(V_{\mathrm{DM}, \mathrm{b}}\right)$, when operating with two-level and three-level modulation.

heatsink and the ground sheet, as can be seen in Fig. 19. The power modules are electrically insulated from the heatsink by the internal ceramic substrate and the star point of the RL-load is floating. The measured waveforms of the parasitic currents through the ground plate can be seen in Fig. 20(a) and 20(b). At each switching event, a displacement current is triggered, generating broadband emissions. It can be seen that the three-level modulation reduces the peak of the current spikes by about $50 \%$, which is consistent with the previously measured noise reduction of about $6 \mathrm{~dB}$. In the logarithmic plot shown in Fig. 20, the characteristic of the AML at $1 \mathrm{MHz}$ 


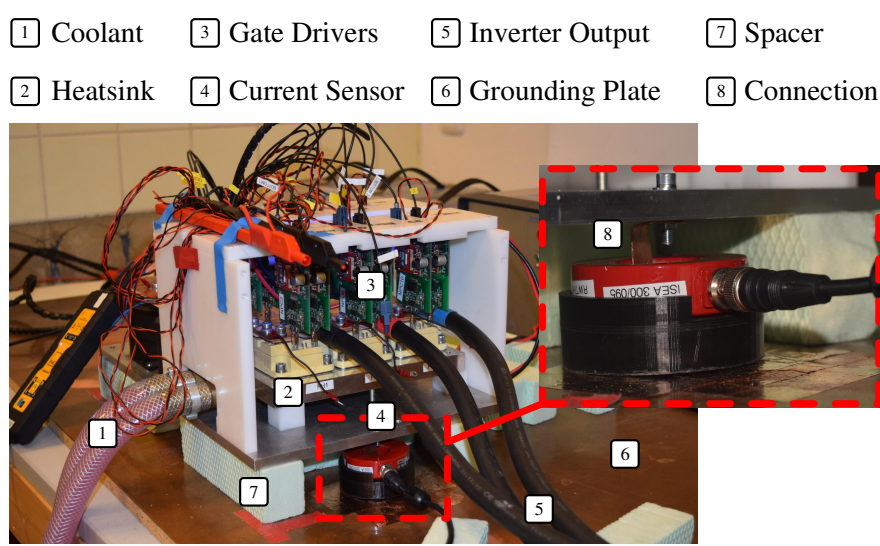

Fig. 19: Current sensor mounting to measure the parasitic current through the ground plate.

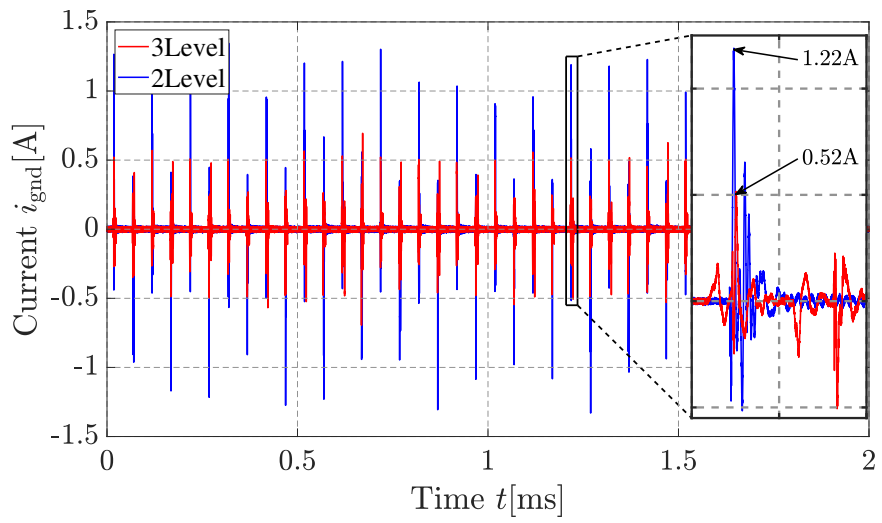

(a)

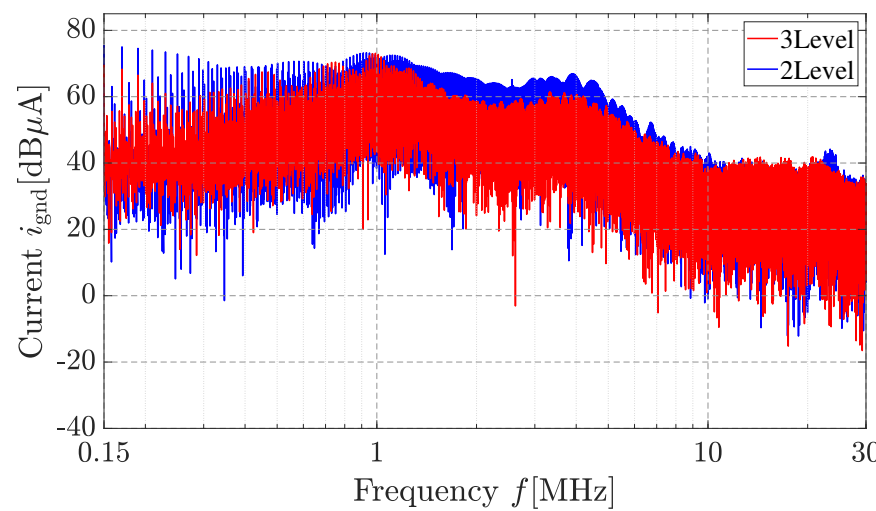

(b)

Fig. 20: Measured parasitic current through the ground plate (a) in time and (b) in frequency domain.

can be recognized and it can be seen that the emissions at the sidebands are reduced by about 3 to $6 \mathrm{~dB}$. This in turn confirms the acquired CM results of the separators.

\section{CONCLUSION}

Due to the additional neutral point connection, the threelevel NPC inverter's DC side forms a three-wire CM/DM system. This paper has presented an approach to separate the three-wire noise of a three-level NPC inverter with a connected neutral point, using two different hardware separators based on small circuit HF transformers. Two very compact separator prototypes have been built and their CM/DM frequency characteristics have been measured, showing reasonable noise transmission and rejection ratios. An EMI testbed with three LISNs has been used to measure the conducted noise of the NPC inverter. A simple three-wire CM model has been introduced to explain the characteristic $\mathrm{CM}$ resonances of the test setup and a short derivation of the DM power module oscillations using two and three-level output voltage modulation has been given. For the investigation, the inverter has been operated with three-level and two-level modulation, resembling normal operation and operation under fault condition, respectively. The noise has been separated into $\mathrm{CM}$, line and phase-DM quantities. The CM noise is predominant. The two typical resonance points of the testbed, caused by the LISN and the AML, could be clearly identified by both separators. Furthermore, the resonance frequency of the power module oscillations, including their dependency on the modulation technique, have been modeled and significantly measured by both the phase-DM and the line-DM separator. Additionally, it has been shown that the two-level in comparison to the threelevel operation increases the noise levels by 3 to $6 \mathrm{~dB}$ and the measured parasitic current through the ground plate confirms the CM noise increase of about $50 \%$.

Thus, it can be concluded that the compact hardware separators could be easily used to identify critical CM and DM noise levels so that an EMI filter can be accordingly designed.

\section{ACKNOWLEDGMENT}

The authors gratefully acknowledge the financial support provided by the Swedish Energy Agency and the German Federal Ministry of Education and Research (BMBF, support code 16EMO0176).

\section{REFERENCES}

[1] A. Kersten, K. Oberdieck, J. Gossmann, A. Bubert, R. Loewenherz, M. Neubert, E. Grunditz, T. Thiringer, and R. W. De Doncker, " $\mathrm{Cm}$ line$\mathrm{dm}$ noise separation for three-level npc inverter with connected neutral point for vehicle traction applications," in 2019 IEEE Transportation Electrification Conference and Expo (ITEC), June 2019, pp. 1-6.

[2] CISPR 25:2016, "Vehicles, boats and internal combustion engines - radio disturbance characteristics - limits and methods of measurement for the protection of on-board receivers," $4^{\text {th }}$ Edition, $27^{\text {th }}$ October 2016.

[3] MIL-STD 461:2015, "Military standard: Electromagnetic interference characteristics requirements for equipment," Version G, December 2015.

[4] SAE Recommended Practice J1113/41:2006, "Limits and methods of measurement of radio disturbance characteristics of components and modules for the protection of receivers used on board vehicles," $29^{\text {th }}$ September 2006

[5] H. Zhang, L. M. Tolbert, and B. Ozpineci, "Impact of sic devices on hybrid electric and plug-in hybrid electric vehicles," IEEE Transactions on Industry Applications, vol. 47, no. 2, pp. 912-921, 2011.

[6] L. Middelstaedt, J. Wang, B. H. Stark, and A. Lindemann, "Direct approach of simultaneously eliminating emi-critical oscillations and decreasing switching losses for wide bandgap power semiconductors," IEEE Transactions on Power Electronics, vol. 34, no. 11, pp. 10376 10380, Nov 2019.

[7] A. Dutta and S. S. Ang, "Electromagnetic interference simulations for wide-bandgap power electronic modules," IEEE Journal of Emerging and Selected Topics in Power Electronics, vol. 4, no. 3, pp. 757-766, Sep. 2016.

[8] X. Gong and J. A. Ferreira, "Comparison and reduction of conducted emi in sic jfet and si igbt-based motor drives," IEEE Transactions on Power Electronics, vol. 29, no. 4, pp. 1757-1767, April 2014. 
[9] K. Oberdieck, J. Gossmann, A. Bubert, and R. W. De Doncker, "Common- and differential-mode separators including the fmbroadcasting band," in PCIM Europe 2018; International Exhibition and Conference for Power Electronics, Intelligent Motion, Renewable Energy and Energy Management, June 2018, pp. 1-8.

[10] K. Oberdieck, A. Sewergin, and R. W. De Doncker, "Influence of the voltage-dependent output capacitance of sic semiconductors on the electromagnetic interference in dc-dc converters for electric vehicles,' in 2017 International Symposium on Electromagnetic Compatibility EMC EUROPE, Sep. 2017, pp. 1-6.

[11] K. Oberdieck, A. Wienhausen, A. Sewergin, A. Stippich, J. Henn, and R. W. De Doncker, "Electromagnetic Emissions by Three Different Concepts of Bidirectional Multi-Phase SiC DC-DC Boost Converters," in Conference for Power Electronics, Intelligent Motion, Renewable Energy and Energy Management (PCIM Europe), 2019.

[12] A. Bubert, K. Oberdieck, H. Xu, and R. W. De Doncker, "Experimental validation of design concepts for future ev-traction inverters," in 2018 IEEE Transportation Electrification Conference and Expo (ITEC), June 2018, pp. 795-802.

[13] Haoran Zhang, A. Von Jouanne, Shaoan Dai, A. K. Wallace, and Fei Wang, "Multilevel inverter modulation schemes to eliminate commonmode voltages," IEEE Transactions on Industry Applications, vol. 36 no. 6, pp. 1645-1653, Nov 2000.

[14] P. Liu, S. Duan, C. Yao, and C. Chen, "A double modulation wave cbpwm strategy providing neutral-point voltage oscillation elimination and $\mathrm{cmv}$ reduction for three-level npc inverters," IEEE Transactions on Industrial Electronics, vol. 65, no. 1, pp. 16-26, Jan 2018.

[15] H. Zhang, L. Yang, S. Wang, and J. Puukko, "Common-mode emi noise modeling and reduction with balance technique for three-level neutral point clamped topology," IEEE Transactions on Industrial Electronics, vol. 64, no. 9, pp. 7563-7573, Sep. 2017.

[16] A. Kersten, O. Theliander, E. A. Grunditz, T. Thiringer, and M. Bongiorno, "Battery loss and stress mitigation in a cascaded h-bridge multilevel inverter for vehicle traction applications by filter capacitors," IEEE Transactions on Transportation Electrification, vol. 5, no. 3, pp. 659-671, Sep. 2019.

[17] D. G. Holmes and T. A. Lipo, Pulse width modulation for powe converters: principles and practice. John Wiley \& Sons, 2003, vol. 18.

[18] L. M. Tolbert, F. Z. Peng, and T. G. Habetler, "Multilevel inverters for electric vehicle applications," in Power Electronics in Transportation (Cat. No.98TH8349), Oct 1998, pp. 79-84

[19] D. Ronanki and S. S. Williamson, "Modular multilevel converters for transportation electrification: Challenges and opportunities," IEEE Transactions on Transportation Electrification, vol. 4, no. 2, pp. 399407, June 2018

[20] A. Kersten, E. Grunditz, and T. Thiringer, "Efficiency of active threelevel and five-level npc inverters compared to a two-level inverter in a vehicle," in 2018 20th European Conference on Power Electronics and Applications (EPE'18 ECCE Europe), Sep. 2018, pp. P.1-P.9.

[21] A. Nabae, I. Takahashi, and H. Akagi, "A new neutral-point-clamped pwm inverter," IEEE Transactions on industry applications, no. 5, pp. 518-523, 1981.

[22] G. I. Orfanoudakis, M. A. Yuratich, and S. M. Sharkh, "Analysis of dclink capacitor current in three-level neutral point clamped and cascaded h-bridge inverters," IET Power Electronics, vol. 6, no. 7, pp. 1376-1389, August 2013.

[23] H. Xu, A. Bubert, M. Laumen, and R. W. De Doncker, "Active neutralpoint balancing of three-level neutral-point-clamped traction inverters," in 2018 21st International Conference on Electrical Machines and Systems (ICEMS), Oct 2018, pp. 2256-2261.

[24] M. Laumen, M. Schubert, A. Bubert, A. Lamprecht, and R. W. De Doncker, "Optimized space vector modulation for dc-link balancing in three-level neutral-point-clamped inverters for electric drives," in 2017 IEEE 12th International Conference on Power Electronics and Drive Systems (PEDS), Dec 2017, pp. 1,135-1,140.

[25] A. Kersten, K. Oberdieck, A. Bubert, M. Neubert, E. Grunditz, T. Thiringer, and R. W. De Doncker, "Fault detection and localization for limp home functionality of three-level npc inverters with connected neutral point for electric vehicles," IEEE Transactions on Transportation Electrification, pp. 1-1, 2019.

[26] J. J. Nelson, W. Goodwin, M. Steffka, W. Ivan, and M. Kopp, "High voltage automotive emc component measurements using an artificial network," in 2007 18th International Zurich Symposium on Electromagnetic Compatibility, 2007, pp. 195-200.
[27] M. Reuter, S. Tenbohlen, W. Köhler, and A. Ludwig, "Impedance analysis of automotive high voltage networks for emc measurements," in 10th International Symposium on Electromagnetic Compatibility, 2011, pp. 106-111.

[28] M. C. Caponet and F. Profumo, "Devices for the separation of the common and differential mode noise: design and realization," in APEC. Seventeenth Annual IEEE Applied Power Electronics Conference and Exposition (Cat. No. 02CH37335), vol. 1. IEEE, 2002, pp. 100-105.

[29] A. Nagel and R. W. De Doncker, "Separating common mode and differential mode noise in emi measurement," EPE Journal, vol. 10, no. 2, pp. 27-30, 2000.

[30] M. L. Heldwein, "Emc filtering of three-phase pwm converters," $\mathrm{Ph} . \mathrm{D}$. dissertation, ETH Zurich, 2008.

[31] M. L. Heldwein, J. Biela, H. Ertl, T. Nussbaumer, and J. W. Kolar, "Novel three-phase $\mathrm{cm} / \mathrm{dm}$ conducted emission separator," IEEE Transactions on Industrial Electronics, vol. 56, no. 9, pp. 3693-3703, Sep. 2009.

[32] S. Wang, F. Luo, and F. C. Lee, "Characterization and design of threephase emi noise separators for three-phase power electronics systems," IEEE Transactions on Power Electronics, vol. 26, no. 9, pp. 2426-2438, Sep. 2011.

[33] S. Wang, "Modeling and design of emi noise separators for multiphase power electronics systems," IEEE Transactions on Power Electronics, vol. 26, no. 11, pp. 3163-3173, Nov 2011.

[34] CISPR 14-12005, "Electromagnetic compatibility - requirements for household appliances, electric tools and similar apparatus - part 1 : Emission," $6^{\text {th }}$ Edition, $11^{\text {th }}$ November 2005.

[35] G. Mademlis, Y. Liu, and N. Saadat, "Combined voltage balancing techniques of the dc link in five-level medium voltage npc back-to-back converters for offshore renewable generation," in 2017 19th European Conference on Power Electronics and Applications (EPE'17 ECCE Europe), Sep. 2017, pp. P.1-P.10.

[36] Plexim GmbH, "Plecs - user manual," https://www.plexim.com/sites/ default/files/plecsmanual.pdf, User Manual, (Accessed on 04/04/2019).

[37] F. Helling, M. Kuder, A. Singer, S. Schmid, and T. Weyh, "Low voltage power supply in modular multilevel converter based split battery systems for electrical vehicles," in 2018 20th European Conference on Power Electronics and Applications (EPE'18 ECCE Europe), Sep. 2018, pp. P.1-P.10.

[38] Mini-Circuits, “Tc1-42x+.pdf," https://ww2.minicircuits.com/pdfs/ TC1-42X+.pdf, Datasheet HF-Transformer, (Accessed on 03/26/2019).

[39] D. Zhang, T. Fan, P. Ning, and X. Wen, "An automatic emi filter design methodology for electric vehicle application," in 2017 IEEE Energy Conversion Congress and Exposition (ECCE), 2017, pp. 4497-4503.

[40] Semikron GmbH, http://www.farnell.com/datasheets/1899262.pdf, Datasheet IGBT Module, (Accessed on 04/04/2019).

[41] H. W. van der Broeck and H. . Skudelny, "Analytical analysis of the harmonic effects of a pwm ac drive," IEEE Transactions on Power Electronics, vol. 3, no. 2, pp. 216-223, 1988.

[42] CISPR 16-x-y series, "Specification for radio disturbance and immunity measuring apparatus and methods," Introduced in 2003.

[43] P. Hillenbrand, S. Tenbohlen, C. Keller, and K. Spanos, "Understanding Conducted Emissions from an Automotive Inverter Using a CommonMode Model," in IEEE International Symposium on Electromagnetic Compatibility, 2015.

[44] K. Oberdieck, A. H. Wienhausen, A. Sewergin, A. Stippich, J. Henn, and R. W. De Doncker, "Electromagnetic emissions by three different concepts of bidirectional multi-phase sic dc-dc boost converters,' in PCIM Europe 2019; International Exhibition and Conference for Power Electronics, Intelligent Motion, Renewable Energy and Energy Management, May 2019, pp. 1-9.

[45] D. Costinett, D. Maksimovic, and R. Zane, "Circuit-oriented treatment of nonlinear capacitances in switched-mode power supplies," IEEE Transactions on Power Electronics, vol. 30, no. 2, pp. 985-995, Feb 2015.

[46] K. Sharifabadi, L. Harnefors, H.-P. Nee, S. Norrga, and R. Teodorescu, Design, control, and application of modular multilevel converters for HVDC transmission systems. John Wiley \& Sons, 2016.

[47] A. Bubert, J. Zhang, and R. W. De Doncker, "Modeling and measurement of capacitive and inductive bearing current in electrical machines," in 2017 Brazilian Power Electronics Conference (COBEP), Nov 2017, pp. $1-6$. 